\title{
Detection of a large rearrangement in PALB2 in Spanish Breast Cancer Families with male breast cancer
}

Ana Blanco ${ }^{1}$, Miguel de la Hoya ${ }^{2}$, Judith Balmaña ${ }^{3}$, Teresa Ramón y Cajal ${ }^{4}$, Alex Teulé ${ }^{5}$, MaríaDolores Miramar ${ }^{6}$, Eva Esteban ${ }^{7}$, Mar Infante ${ }^{8}$, Javier Benítez ${ }^{9}$, Asunción Torres ${ }^{10}$, , María-Isabel Tejada $^{11}$, Joan Brunet ${ }^{12}$, Begoña Graña ${ }^{13}$, Milagros Balbín ${ }^{14}$, Pedro Pérez-Segura ${ }^{15}$, Ana Osorio ${ }^{9}$,

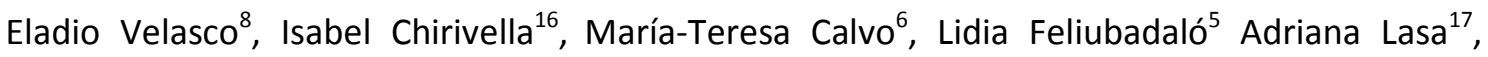
Orland Díez $^{18}$, Angel Carracedo $^{1}$, Trinidad Caldés ${ }^{2}$, Ana Vega $^{1 *}$

${ }^{1}$ Fundación Pública Galega de Medicina Xenómica-SERGAS, Grupo de Medicina Xenómica-USC, CIBER-ER, IDIS, Spain.

${ }^{2}$ Laboratorio de Oncología Molecular, Hospital Clínico San Carlos, Madrid, Spain.

${ }^{3}$ Servicio de Oncología Médica, Hospital Universitari Vall d’Hebron, Barcelona, Spain.

${ }^{4}$ Servei de Oncología, Hospital de la Santa Creu i Sant Pau, Barcelona, Spain.

${ }^{5}$ Programa de Cáncer Hereditario, Instituto Catalán de Oncología, IDIBELL-ICO, L'Hospitalet de Llobregat, Barcelona, Spain.

${ }^{6}$ Unidad de Genética. Servicio de Bioquímica. Hospital Universitario Miguel Servet, Zaragoza, Spain.

${ }^{7}$ Laboratorio de Biología Molecular, Servicio de Análisis Clínicos, Hospital Universitario La Fe, Valencia, Spain.

8 Grupo de Genética del Cáncer, Instituto de Biología y Genética Molecular (UVa-CSIC), Valladolid, Spain.

${ }^{9}$ Grupo de Genética Humana, Centro Nacional de Investigaciones Oncológicas-CNIO, CIBER-ER Madrid, Spain.

${ }^{10}$ Unitat de Consell Genètic, Hospital Universitari Sant Joan, Reus, IISPV, Spain.

11 Laboratorio de Genética Molecular-Servicio de Bioquímica, Hospital de Cruces, Barakaldo, Spain.

${ }^{12}$ Programa de Cáncer Hereditario, Institut Català d'Oncologia, IDIBGI, Girona, Spain.

${ }^{13}$ Oncoloxía Médica / UARC-Consello Xenético, Hospital Arquitecto Marcide, Área Sanitaria de Ferrol, A Coruña, Spain.

14 Laboratorio de Oncología Molecular-IUOPA (Instituto Universitario de Oncología del Principado de Asturias), Hospital Universitario Central de Asturias, Oviedo, Spain.

${ }^{15}$ Servicio de Oncología Médica, Hospital Clínico San Carlos, Madrid, Spain

${ }^{16}$ Unidad de Consejo Genético en Cáncer, Hospital Clínico Universitario, Valencia, Spain.

${ }^{17}$ Servei de Genètica, Hospital de la Santa Creu i Sant Pau, Barcelona, Spain.

18 Programa de Medicina Molecular. Hospital Universitari Vall d'Hebron; Laboratori d'Oncogenetica. Vall d'Hebron Institut d'Oncologia (VHIO), Barcelona, Spain.

*Correspondence to: Ana Vega, Fundación Pública Galega de Medicina Xenómica, c/Choupana s/n, Edificio de Consultas, Planta -2, Hospital Clínico, Santiago de Compostela, Spain. E-mail: ana.vega@usc.es 


\section{ABSTRACT}

It has been demonstrated that monoallelic PALB2 (Partner and Localizer of BRCA2) gene mutations predispose to familial breast cancer. Some of the families reported with germline PALB2 mutations presented male breast cancer as a characteristic clinical feature. Therefore, we wanted to investigate the contribution of germline PALB2 mutations in a set of 131 Spanish $B R C A 1 / B R C A 2$-negative breast/ovarian cancer families with at least one male breast cancer case. The analysis included direct sequencing of all coding exons and intron/exon boundaries as well as a Multiplex Ligation-dependent Probe Amplification-based analysis of genomic rearrangements. For the first time we have identified a genomic rearrangement of PALB2 gene involving a large deletion from exon 7 to 11 in a breast cancer family. We have also identified several PALB2 variants, but no other obvious deleterious PALB2 mutation has been found. Thus, our study does not support an enrichment of PALB2 germline mutations in the subset of breast cancer families with male breast cancer cases. The identification of intronic and exonic variants indicates the necessity of assessing the implications of variants that do not lead to PALB2 truncation in the pathoghenicity of the PALB2 gene.

Keywords: Familial breast cancer; PALB2; Male Breast Cancer; genomic rearrangement; $B R C A 1 / B R C A 2-$ negative families, in silico analysis

\section{INTRODUCTION}

Breast cancer with an autosomal dominant pattern of inheritance accounts for $5-10 \%$ of all breast cancer cases. Between $20-25 \%$ of inherited breast cancer can be traced to germline mutations in BRCA1 and BRCA2 genes. Other genes participating in DNA damage response pathways such as CHEK2, ATM and FANCJ/BRIP1 are also involved in familial breast cancer [1].

The PALB2 (for "partner and localizer of BRCA2") gene encodes a protein that participates in genome maintenance through double strand break repair. PALB2 protein binds to the BRCA2 N-terminal end stabilizing it in key nuclear structures, which allows BRCA2 to function in DNA repair and at the S-phase checkpoint [2]. PALB2 co-localizes with BRCA2 being essential for key BRCA2 nuclear caretaker functions, implying that PALB2 could be also considered a tumor-suppressor gene [3]. Recent studies have shown that PALB2 not only interplay with BRCA2, but also mediates the interaction between BRCA1 and BRCA2 in the DNA-damage response [4]. BRCA1 acts in this complex as an upstream regulator of PALB2 and 
BRCA2 in the DNA-damage response and is important for targeting PALB2 and BRCA2 to DNAdamage sites [4]. PALB2 and BRCA2 act together to deliver RAD51, another DNA double strand break repair, to the chromosomal lesion in order to initiate DNA repair. Moreover, it has been recently shown that PALB2 binds DNA and physically interacts with RAD51 exerting a stimulatory effect on the ability of RAD51 to make D-loops [5].

BRCA2 is also known as FANCD1, which is a Fanconi anemia protein. Biallelic mutations in BRCA2 and PALB2, respectively, underlie Fanconi anemia complementation groups FA-D1 and FA-N. However, clinical phenotype of these patients is strikingly different from that reported in classical Fanconi anemia [6]. In particular, FA-D1 and FA-N are associated with higher risks of solid childhood malignancies such as Wilms tumor and medulloblastoma, which occur very rarely in other subtypes of Fanconi anemia. Monoallelic PALB2 mutations have also been confirmed to cause moderate-penetrance breast cancer susceptibility [2], accounting for about $1 \%$ of BRCA1/BRCA2 negative familial and early breast cancer [7][8][9]. PALB2 is responsible for $1-2 \%$ of young breast cancer patients unselected for breast family history in Chinese and white South African populations [10] [11]. None of the breast cancer cases with PALB2 germline mutations reported to date have been found to show loss of hererozygosity $(\mathrm{LOH})$ at this locus. This lack of $\mathrm{LOH}$ has raised speculation on alternative mechanisms of PALB2 functional inactivation [7].

To date, studies examining PALB2 gene in specific populations have been carried out, identifying recurrent mutations such as c.2323C $>T$ (p.Q775X) in French Canadians [9], c.1592delT (p.L531fs) in Finnish [12] or c.751C>T (p.Q251X) in Chinese population [10].

Recently, a potential connection between PALB2 truncating mutations and male breast cancer arose from several studies. Rahman et al. (2007)[6] detected that the prevalence of truncating mutations was higher in families with both male and female breast cancer (6.7\%) than in families with only breast cancer cases in females (1\%). Moreover, more recently Garcia et al. (2009)[7] analyzed PALB2 germline mutations in a cohort of 95 BRCA1/BRCA2-negative Spanish breast/ovarian cancer families, identifying only one frameshift alteration (c.1056_1057delGA; p.K353IfsX7). Interestingly, the mutation was detected in a family with a male breast cancer, further supporting that male breast cancer is a clinical characteristic feature of PALB2 autosomal dominant breast cancer syndromes.

The present study attempts to evaluate for the first time in the Spanish population, the contribution of germline PALB2 mutations in 131 BRCA1/BRCA2-negative high-risk breast/ovarian cancer families with at least one case of male breast cancer. 


\section{MATERIAL AND METHODS}

\section{Patients}

Index cases from 131 BRCA1/BRCA2 mutation-negative Spanish high-risk breast/ovarian cancer families with at least one male breast cancer case were screened for mutations within the entire coding sequence and splicing sites of PALB2 gene. Families were ascertained through 12 different Spanish centres (Supplementary Table 1). Clinical characteristics of the families are represented in Table 1. The ethics committee approvals as well as informed consent from the patients were obtained for the study.

All index cases had been previously screened for point mutations and large rearrangement mutations in BRCA1 and BRCA2 genes and were found to be negative.

\section{Mutation analysis of PALB2 gene}

DNA samples were obtained from peripheral blood leukocytes using standard procedures. The entire coding sequence of PALB2 along with flanking intron boundaries were amplified using primers designed with Primer3 software (http://frodo.wi.mit.edu/cgibin/primer3/primer3_www.cgi). Primer sequences and melting temperatures are shown in Supplementary table 2. A negative control was used in each PCR. PCR quality was checked on Agilent 2100 Expert Bioanalyzer (Agilent Technologies Inc. Santa Clara, CA USA). Then, PCR products were purified by "Exosap-it" (USB Corporation, Cleveland, Ohio) and bi-directional sequencing reaction was performed with "Big Dye Terminator v3.1 Cycles Sequencing Kit" (Applied Byosistems, Warrington, UK) on ABI PRISM 3730xI Genetic Analyzer (Applied Biosystems, Foster City, CA, USA) in accordance with the manufacturer's instructions. Sequences were performed using the PCR primers with the exception of exon 13 (see supplementary table 2). Sequences were examined using Staden Package software (Open Source Technology Group, Inc).

Multiplex ligation-dependent probe amplification (MLPA) to detect genomic rearrangements of PALB2 was performed using the FANCD2-PALB2 kit (P057) from MRCHolland (Amsterdam, The Netherlands) in accordance with the manufacturer's protocol. The samples were run and analyzed on the ABI PRISM 3730xl Genetic Analyzer (Applied Biosystems) using fragment analysis tools. Analysis was repeated using an independent sample in an independent assay for positive DNA samples of a genomic rearrangement. Analysis of 
MLPA results was performed visually and by Coffalyser MLPA-DAT from MRC-Holland using direct analysis as analysis method to normalization.

\section{In silico analysis}

Briefly, splicing predictions were performed with SpliceSiteFinder [13], MaxEntScan [14], NNSplice [15] and GeneSplicer [16] algorithms. Biological significance was suspected only if two algorithms predicted a splice site score variation greater than 10\% [17]. Amino acid substitutions were tested with PolyPhen-2 (http://genetics.bwh.harvard.edu/pph2/), SIFT (http://sift.jcvi.org/) and Align-GVGD (http://agvgd.iarc.fr/) tools. All in silico analysis were performed using Alamut- Mutation Interpretation Software v.1.54 (http://www.interactivebiosoftware.com/alamut.html).

\section{Nomenclature and databases}

Sequences used for PALB2 nomenclature were obtained from the NCBI RefSeq database (NG_007406.1 for genomic, NM_024675.3 for mRNA and NP_078951.2 for protein) (http://www.ncbi.nlm.nih.gov)). The nomenclature follows the recommendations from the Human Genome Variation Society (HGVS, www.hgvs.org/mutnomen/) [18].

\section{RESULTS}

We sequenced all exons and intronic boundaries of PALB2 gene and we also carried out MLPA analysis in 131 index cases from BRCA1/BRCA2-negative high-risk Spanish breast/ovarian cancer families with at least one male breast cancer.

We identified a large deletion spanning from exon 7 to 11 (c.2587-?_3201+?del) (Figure 1), in a woman diagnosed with breast cancer at 70 years of age. The proband had a brother diagnosed both with breast cancer at 75 years and gastric cancer after the initial breast cancer diagnosis (Figure 2). To confirm segregation with disease, we tested for the presence of the PALB2 deletion in the paraffined breast tumoral sample of the affected brother. MLPA analysis demonstrated the presence of the alteration. Interestingly, we observed a dosage reduction close to $75 \%$ for exons 7 to 11 together with a dosage reduction in the $25 \%-50 \%$ range for the remaining exons (the only exception being exon1, in which no dosage reduction was observed). The data might be compatible with partial loss of the wild type allele (exons 2 to 13 ) in the tumor (Figure 1). 
In addition to this deletion, we also identified seventeen PALB2 germline variants, although none of them was predicted to result in a truncated protein product (Table 2). Seven of them were novel (c.-200-27T>G; c.-158G>T; c.620C>G (p.Pro207Arg); c.1684+29A>G; c. $2586+58 \mathrm{C}>\mathrm{T}$; c.2587-38C $>\mathrm{G}$; c.2865T $>A$ (p.Ser955Arg)) and all of them except c.2586+58C $>\mathrm{T}$ were found once in our samples. The variants c. $-47 \mathrm{G}>\mathrm{A}, \mathrm{c} .212-58 \mathrm{~A}>\mathrm{C}$, c.1010T>C (p.Leu337Ser), c.1194G>A (p.=), and c.1572A>G (p.=), c.1676A>G (p.GIn559Arg), c.2014G>C (p.Glu672GIn), c.2590C>T (p.Pro864Ser), c.2993G>A (p.Gly998GIn) and c.3300T>G (p.=) had been previously reported $[7,10,12,19-23]$.

The results of bioinformatic predictions for intronic and missense variants are represented in Table 3. Interestingly, three of the missense variants, c.620C >G (p.Pro207Arg), c.1010T>C (p.Leu337Ser), and c.2993G>A (p.Gly998GIn), were predicted to likely affect PALB2 protein function by all the tested algorithms. Unfortunately, it was not possible to do segregation analysis in the families for any of these variants. The bioinformatic splicing analyses do not show variations in the consensus site scores. For variants c.-200-27T>G, c.47G >A, c.1676A>G (p.GIn559Arg), and c.2590C >T (p.Pro864Ser), a reduction of $100 \%$ in a cryptic splice site score is predicted for at least two algorithms. MaxEntScan and NNSplice algorithms predicted an increase in the score of the cryptic site c.2597 in 11.2 and $22.8 \%$, by the variant c.2590C $>$ T (p.Pro864Ser).

There were six index cases sharing six different variants: c.212-58A $>C$, c.1676A $>G$ (p.Gln559Arg), c.2014G>C (p.Glu672GIn), c.2586+58C>T, c.2993G>A (p.Gly998GIn) and c.3300T>G (p.=). The variants c.1676A>G (p.GIn559Arg) and c.2586+58C>T were also present in other cases, and the former is predicted by the bioinformatic software to probably affect PALB2 protein function. In order to identify if these six variants were inherited together, cosegregation analysis in one of the carrier families was performed. Our results suggest that all the six variants constituted a haplotype (Supplementary figure 1) that is present in the two breast cancer patients of the analyzed family.

\section{DISCUSSION}

PALB2 mutations have recently been shown to confer a moderate risk to develop breast cancer [6]. It has been reported that families carrying protein-truncating PALB2 mutations shown cases of male breast cancer [6, 7]. Given the increased risk of male breast cancer associated with carrying a germline BRCA2 mutation and the functional relationship between $B R C A 2$ and $P A L B 2$, the male PALB2 mutation carriers might be at an increased risk of breast cancer. 
Until now more than 26 PALB2 truncating mutations have been reported [20, 22, 2426], 22 of them found in breast cancer families. Although large genomic rearrangements in PALB2 have been analysed in studies of familial breast cancer $[9,20,27,28]$, the unique large genomic mutation detected in PALB2 was c.71-?_561+?del. This genomic change was identified in a Fanconi Anemia patient, and it implies the deletion of exons 2, 3 and 4 [29]. In our series of 131 index cases from Spanish BRCA1/BRCA2-negative breast/ovarian cancer families with a male breast cancer case, we identified a large rearrangement in one breast cancer index case. The mutation c.2587-?_3201+?del detected in our population is a large deletion comprising exons 7 to 11 . Our finding provides the first evidence that large genomic changes in PALB2 also contribute to hereditary breast cancer in families BRCA1/BRCA2 negatives.

To date, all PALB2 mutations reported as pathogenic result in premature protein truncation [6], and were identified in about $1 \%$ of familial breast cancer. In breast cancer families with both female and male breast cancer cases, frequency of PALB2 mutations increased to $6.7 \%(1 / 15)$ in the UK series of Rahman et al [6] and to $9 \%(1 / 11)$ in the Spanish series of Garcia et al [7]. Although these previous series of families with male breast cancer were small, results seemed to suggest a higher implication of PALB2 mutations within this type of families. In the present study, we analysed 131 Spanish female and male breast cancer families extending the mutation detection analysis to detect large genomic rearrangements of PALB2 by using Multiplex ligation-dependent probe amplification (MLPA).The frequency of PALB2 mutations found was $0.75 \%$, which is similar to the $1 \%$ frequency previously reported for breast cancer families not selected for male breast cancer. However, we cannot rule out the potential pathogenicity of non truncating PALB2 variants. It has been shown that the $\mathrm{N}$ terminal coiled-coil motif of PALB2 (residues 1-319) interacts with the coiled-coil domain of BRCA1 $[4,30]$, whereas the C-terminal WD40 repeats of PALB2 (residues 836-1186) associate with the N-terminus of BRCA2 $[3,4,31]$. Thus, PALB2 missense variants in these domains might be pathogenic. From the missense variants identified in our study, c.620C $>G$ (p.Pro207Arg) is located in the coiled-coil domain of PALB2, whereas c.2590C $>T$ (p.Pro864Ser), c.2865T>A (p.Ser955Arg) and c.2993G>A (p.Gly998GIn) are located in the C-terminal domain of the protein. Moreover variants c.620C>G (p.Pro207Arg), c.1010T>C (p.Leu337Ser), and c.2993G>A (p.Gly998GIn) have been predicted as pathogenic by the three amino acidic algorithms (Table 3). 
As for other genes, the possibility of intronic variants of PALB2 being implicated in the splicing process should not be discarded. Besides, functional analysis for variants that could regulate gene expression should also being considered.

The MLPA analysis of the breast tumor sample FFPE tissue from the carrier of exon 7-11 deletion suggests partial loss of the wild type PALB2 allele (exons 2 to 13) which in turns could support previous evidences that PALB2 loss of function might also conform to the inactivation model of a classic tumor-suppressor gene [7]. Yet, great caution should be taken when interpreting MLPA analysis of FFPE tissue

In summary, our work identifies for the first time a genomic rearrangement of PALB2 gene in a $B R C A 1 / B R C A 2$ mutation-negative Spanish cancer family with at least one male breast cancer case. If we considered only PALB2 truncation variants as pathogenic, the frequency of PALB2 mutations in high-risk families with male breast cancer is similar to that reported for high-risk families not selected by the presence of male breast cancer. However, more studies to assess the implication of PALB2 variants that do not originate PALB2 truncation (missense changes, small in-frame insertions or deletions and potential splice site alterations) are required.

\section{Acknowledgments}

We are grateful to the families for their cooperation and to the clinical personnel involved in aspects of recruitment and clinical data collection. This work was supported by grants from the Xunta de Galicia (10PXIB 9101297PR) and FMM Foundation given to AV. TC, M de H and PPS were supported by PS09/00859, RD06/0020/0021 from RTICC, Instituto de Salud Carlos III. JB and AO were supports by the AECC, and RD06/0020/1060 from RTICC ICO: Contract grant sponsor: Asociación Española Contra el Cáncer, Spanish Health Research Fund; Carlos III Health Institute; Catalan Health Institute and Autonomous Government of Catalonia. Contract grant numbers: ISCIIIRETIC RD06/0020/1051, PI10/01422, PI10/31488 and 2009SGR290. E.V. grants, CSI004A10-2 (Consejería de Educación, Junta de Castilla y León) and BIO39/VA27/10 (Consejería de Sanidad, Junta de Castilla y León).

\section{Conflict of interest}

The authors declare no conflict of interest. 


\section{References}

1. Venkitaraman AR (2004) Tracing the network connecting BRCA and Fanconi anemia proteins. Nat Rev Cancer 4:266-276

2. Walsh T, King MC (2007) Ten genes for inherited breast cancer. Cancer Cell 11:103-105

3. Xia B, Sheng Q, Nakanishi K, Ohashi A, Wu J, Christ N, Liu X, Jasin M, Couch FJ, Livingston DM (2006) Control of BRCA2 cellular and clinical functions by a nuclear partner, PALB2. Molecular Cell 22:719-729

4. Zhang $F$, Ma J, Wu J, Ye L, Cai $H$, Xia B, Yu X (2009) PALB2 links BRCA1 and BRCA2 in the DNAdamage response. Curr Biol 19:524-529

5. Dray E, Etchin J, Wiese C, Saro D, Williams GJ, Hammel M, Yu X, Galkin VE, Liu D, Tsai MS, Sy SM, Schild D, Egelman E, Chen J, Sung P (2010) Enhancement of RAD51recombinase activity by the tumor suppressor PALB2. Nat Struct Mol Biol 17:1255-1259

6. Rahman N, Seal S, Thompson D, Kelly P, Renwick A, Elliott A, Reid S, Spanova K, Barfoot R, Chagtai T, Jayatilake H, McGuffog L, Hanks S, Evans DG, Eccles D; Breast Cancer Susceptibility Collaboration (UK), Easton DF, Stratton MR (2007) PALB2, which encodes a BRCA2-interacting protein, is a breast cancer susceptibility gene. Nat Genet 39:165-167

7. Garcia MJ, Fernandez V, Osorio A, Barroso A, Llort G, Lázaro C, Blanco I, Caldés T, de la Hoya M, Ramón Y Cajal T, Alonso C, Tejada MI, San Román C, Robles-Díaz L, Urioste M, Benítez J (2009) Analysis of FANCB and FANCN/PALB2 fanconi anemia genes in BRCA1/2-negative Spanish breast cancer families. Breast Cancer Res Treat 113:545-551

8. Tischkowitz M, Xia B, Sabbaghian N, Reis-Filho JS, Hamel N, Li G, van Beers EH, Li L, Khalil T, Quenneville LA, Omeroglu A, Poll A, Lepage P, Wong N, Nederlof PM, Ashworth A, Tonin PN, Narod SA, Livingston DM, Foulkes WD (2007) Analysis of PALB2/FANCN-associated breast cancer families. PNAS 104:6788-6793

9. Foulkes WD, Ghadirian P, Akbari MR, Hamel N, Giroux S, Sabbaghian N, Darnel A, Royer R, Poll A, Fafard E, Robidoux A, Martin G, Bismar TA, Tischkowitz M, Rousseau F, Narod SA (2007) Identification of a novel truncating PALB2 mutation and analysis of its contribution to earlyonset breast cancer in French-Canadian women. Breast Cancer Res 9:R83

10. Cao AY, Huang J, Hu Z, Li WF, Ma ZL, Tang LL, Zhang B, Su FX, Zhou J, Di GH, Shen KW, Wu J, Lu JS, Luo JM, Yuan WT, Shen ZZ, Huang W, Shao ZM (2009) The prevalence of PALB2 germline mutations in BRCA1/BRCA2 negative Chinese women with earlyonset breast cancer or affected relatives. Breast Cancer Res Treat 114:457-462

11. Sluiter M, Mew S, van Rensburg EJ (2009) PALB2 sequence variants in young South African breast cancer patients. Fam Cancer 8:347-353

12. Erkko H, Xia B, Nikkila J, Schleutker J, Syrjäkoski K, Mannermaa A, Kallioniemi A, Pylkäs K, Karppinen SM, Rapakko K, Miron A, Sheng Q, Li G, Mattila H, Bell DW, Haber DA, Grip M, 
Reiman M, Jukkola-Vuorinen A, Mustonen A, Kere J, Aaltonen LA, Kosma VM, Kataja V, Soini Y, Drapkin RI, Livingston DM, Winqvist R (2007) A recurrent mutation in PALB2 in Finnish cancer families. Nature 446:316-319

13. Zhang MQ (1998) Statistical features of human exons and their flanking regions. Hum Mol Genet 7:919-932

14. Yeo G, Burge CB (2004) Maximum entropy modeling of short sequence motifs with applications to RNA splicing signals. J Comput Biol 11:377-394

15. Reese MG, Eeckman FH, Kulp D, Haussler D (1997) Improved splice site detection in Genie. J Comput Biol 4:311-323

16. Pertea M, Lin X, Salzberg SL (2001) GeneSplicer: a new computational method for splice site prediction. Nucleic Acids Res 29:1185-1190

17. Hellen B (November 2009) Splice Site Tools. A comparative analysis report.

18. den Dunnen JT, Antonarakis SE (2000) Mutation nomenclature extensions and suggestions to describe complex mutations: a discussion. Hum Mutat 15:7-12

19. Rahman N, Scott RH (2007) Cancer genes associated with phenotypes in monoallelic and biallelic mutation carriers: new lessons from old players. Hum Mol Genet 16:R60-R66

20. Papi L, Putignano AL, Congregati C, Piaceri I, Zanna I, Sera F, Morrone D, Genuardi M, Palli D (2010) A PALB2 germline mutation associated with hereditary breast cancer in Italy. Familial Cancer 9:181-185

21. Tischkowitz M, Sabbaghian N, Hamel N, Borgida A, Rosner C, Taherian N, Srivastava A, Holter S, Rothenmund H, Ghadirian P, Foulkes WD, Gallinger S (2009) Analysis of the gene coding for the BRCA2-interacting protein PALB2 in familial and sporadic pancreatic cancer. Gastroenterology 137:1183-1186

22. Dansonka-Mieszkowska A, Kluska A, Moes J, Dabrowska M, Nowakowska D, Niwinska A, Derlatka P, Cendrowski K, Kupryjanczyk J (2010) A novel germline PALB2 deletion in Polish breast and ovarian cancer patients. BMC Med Genet 11:20

23. Silvestri V, Rizzolo P, Zanna I, Falchetti M, Masala G, Bianchi S, Papi L, Giannini G, Palli D, Ottini L (2010) PALB2 mutations in male breast cancer: a population-based study in Central Italy. Breast Cancer Res Treat 122:299-301

24. Jones $S$, Hruban RH, Kamiyama $M$, Borges $M$, Zhang $X$, Parsons DW, Lin JC, Palmisano $E$, Brune K, Jaffee EM, lacobuzio-Donahue CA, Maitra A, Parmigiani G, Kern SE, Velculescu VE, Kinzler KW, Vogelstein B, Eshleman JR, Goggins M, Klein AP (2009) Exomic sequencing identifies PALB2 as a pancreatic cancer susceptibility gene. Science 324:217

25. Balia C, Sensi E, Lombardi G, Roncella M, Bevilacqua G, Caligo MA (2010) PALB2: a novel inactivating mutation in a Italian breast cancer family. Familial Cancer 9:531-536 
26. Hellebrand H, Sutter C, Honisch E, Gross E, Wappenschmidt B, Schem C, Deissler H, Ditsch N, Gress V, Kiechle M, Bartram CR, Schmutzler RK, Niederacher D, Arnold N, Meindl A (2011) Germline mutations in the PALB2 gene are population specific and occur with low frequencies in familial breast cancer. Hum Mutat 32:E2176-E2188

27. Pylkas K, Erkko H, Nikkila J, Sólyom S, Winqvist R (2008) Analysis of large deletions in BRCA1, BRCA2 and PALB2 genes in Finnish breast and ovarian cancer families. BMC Cancer $8: 146$

28. Ameziane N, van den Ouweland AMW, Adank MA, Vijzelaar RN, Errami A, Dorsman JC, Joenje $\mathrm{H}$, Meijers-Heijboer $\mathrm{H}$, Waisfisz Q (2009) Lack of large genomic deletions in BRIP1, PALB2, and FANCD2 genes in BRCA1/2 negative familial breast cancer. Breast Cancer Res Treat 118:651-653

29. Xia B, Dorsman JC, Ameziane N, de Vries Y, Rooimans MA, Sheng Q, Pals G, Errami A, Gluckman E, Llera J, Wang W, Livingston DM, Joenje H, de Winter JP (2007) Fanconi anemia is associated with a defect in the BRCA2 partner PALB2. Nat Genet 39:159-161

30. Sy SM, Huen MS, Chen J (2009) PALB2 is an integral component of the BRCA complex required for homologous recombination repair. PNAS 106:7155-7160

31. Sy SM, Huen MS, Zhu Y, Chen J (2009) PALB2 regulates recombinational repair through chromatin association and oligomerization. J Biol Chem 284:18302-18310 
Table 1. Clinical charactheristics of the 131male and female breast cancer index cases

\begin{tabular}{|c|c|}
\hline \multicolumn{2}{|l|}{ Clinical diagnosis and patient information } \\
\hline Age in years at first diagnosis (years)(male/female) & $58 / 55$ \\
\hline Breast cancer (male/female) & $83 / 36$ \\
\hline Bilateral breast cancer (male/female) & $5 / 4$ \\
\hline Ovarian cancer & 3 \\
\hline Family history of first degree relative with breast cancer (male/female) & $40 / 77$ \\
\hline Family history of second degree relative with breast cancer (male/female) & $18 / 44$ \\
\hline \multicolumn{2}{|l|}{ Other malignancies in family } \\
\hline Gastric & 21 \\
\hline Colon & 17 \\
\hline Prostate & 16 \\
\hline Lung & 7 \\
\hline Ovarian & 6 \\
\hline Leukaemia & 5 \\
\hline Melanoma & 5 \\
\hline Cerebral & 4 \\
\hline Larynx & 3 \\
\hline Kidney & 3 \\
\hline Stomach & 2 \\
\hline Pancreas & 2 \\
\hline Osteosarcoma & 2 \\
\hline Bladder & 2 \\
\hline Throat & 1 \\
\hline Uterus & 1 \\
\hline Lymphoma & 1 \\
\hline Non- Hodgkin Lymphoma & 1 \\
\hline Esophagus & 1 \\
\hline Lips & 1 \\
\hline Cervix & 1 \\
\hline Head-neck & 1 \\
\hline \multicolumn{2}{|l|}{ Multiple malignancies } \\
\hline Breast and prostate cancer & 5 \\
\hline Breast and gastric cancer & 3 \\
\hline Breast cancer and melanoma & 2 \\
\hline Breast and colon cancer & 2 \\
\hline Breast and ovarian cancer & 1 \\
\hline Larynx and stomach cancer & 1 \\
\hline
\end{tabular}


Table 2. PALB2 sequence variants identified in 131 Spanish breast/ovarian cancer families with male breast cancer cases

\begin{tabular}{|c|c|c|c|c|c|c|c|c|}
\hline \multirow{2}{*}{ Location } & \multirow{2}{*}{ Nucleotide change $^{a}$} & \multirow{2}{*}{ Protein change } & \multirow{2}{*}{ Name of SNP } & \multicolumn{3}{|c|}{ Genotypes } & \multicolumn{2}{|c|}{ Allelic frequency $(\%)^{b}$} \\
\hline & & & & $\mathbf{A A}$ & AB & BB & $A(A \%)$ & B (B\%) \\
\hline 5' upstream sequence & c. $-200-27 T>G$ & - & - & 0 & 1 & 130 & $1(0.38)$ & 261 (99.62) \\
\hline \multirow{2}{*}{ EXON1 } & C. $-158 \mathrm{G}>\mathrm{C}$ & - & - & 0 & 1 & 130 & $1(0.38)$ & 261 (99.62) \\
\hline & c. $-47 G>A$ & - & rs8053188 & 0 & 3 & 128 & $3(1.14)$ & 259 (98.86) \\
\hline IVS3 & c. $212-58 \mathrm{~A}>\mathrm{C}$ & - & - & 0 & 6 & 125 & $6(2.29)$ & $256(97.71)$ \\
\hline \multirow{5}{*}{ EXON 4} & c. $620 \mathrm{C}>\mathrm{G}$ & p.Pro207Arg & - & 0 & 1 & 130 & $1(0.38)$ & 261 (99.62) \\
\hline & c.1010T>C & p.Leu337Ser & rs45494092 & 0 & 3 & 128 & $3(1.14)$ & $259(98.86)$ \\
\hline & c.1194G>A & p.Val398Val & rs61755173 & 0 & 1 & 130 & $1(0.38)$ & 261 (99.62) \\
\hline & c. $1572 A>G$ & p.Ser524Ser & rs45472400 & 0 & 1 & 130 & $1(0.38)$ & 261 (99.62) \\
\hline & c. $1676 A>G$ & p.GIn559Arg & rs152451 & 4 & 34 & 93 & $42(16.03)$ & 220 (83.97) \\
\hline IVS4 & c. $1684+29 A>G$ & - & - & 0 & 1 & 130 & $1(0.38)$ & 261 (99.62) \\
\hline EXON 5 & c. $2014 \mathrm{G}>\mathrm{C}$ & p.Glu672GIn & rs45532440 & 0 & 6 & 125 & $6(2.29)$ & $256(97.71)$ \\
\hline \multirow{2}{*}{ IVS6 } & c. $2586+58 C>T$ & - & rs249954 & 7 & 60 & 64 & $74(28.24)$ & $188(71.76)$ \\
\hline & c. $2587-38 C>G$ & - & - & 0 & 1 & 130 & $1(0.38)$ & 261 (99.62) \\
\hline EXON 7 & c. $2590 \mathrm{C}>\mathrm{T}$ & p.Pro864Ser & rs45568339 & 0 & 2 & 129 & $2(0.76)$ & $260(99.24)$ \\
\hline \multirow[t]{2}{*}{ EXON 9} & c.2865T $>A$ & p.Ser955Arg & - & 0 & 1 & 130 & $1(0.38)$ & 261 (99.62) \\
\hline & c. $2993 \mathrm{G}>\mathrm{A}$ & p.Gly998GIn & rs45551636 & 0 & 6 & 125 & $6(2.29)$ & 256 (97.71) \\
\hline EXON 12 & c.3300T>G & p.Thr1100Thr & rs45516100 & 0 & 6 & 125 & $6(2.29)$ & $256(97.71)$ \\
\hline
\end{tabular}

\footnotetext{
${ }^{\mathrm{a}}$ In bold variants not previously reported
}

${ }^{b}$ Allelic frequency is the percentage of $n / N$, where $n$ is the number of times of minor allele and $N$ is the total of alleles. 
Table 3. Results of bioinformatic analysis for PALB2 variants

\begin{tabular}{|c|c|c|c|c|c|c|c|c|c|c|c|c|c|c|c|c|c|}
\hline \multirow[b]{3}{*}{ VARIANT } & \multirow[b]{3}{*}{$\begin{array}{l}\text { PROTEIN } \\
\text { CHANGE }\end{array}$} & \multicolumn{4}{|c|}{$\begin{array}{c}\text { PREDICTION AMINO ACIDIC } \\
\text { CHANGE }\end{array}$} & \multicolumn{12}{|c|}{ SPLICE SIGNAL DETECTION } \\
\hline & & \multirow[b]{2}{*}{ POLYPHEN } & \multirow[b]{2}{*}{ SIFT } & \multirow[b]{2}{*}{$\begin{array}{l}\text { A- } \\
\text { GVGD }\end{array}$} & \multirow[b]{2}{*}{ Site $^{a}$} & \multicolumn{3}{|c|}{ SSF [0-100] } & \multicolumn{3}{|c|}{ MaxEnt [0-12] } & \multicolumn{3}{|c|}{ NNSPLICE $[0-1]$} & \multicolumn{3}{|c|}{ GeneSplicer [0-15] } \\
\hline & & & & & & $\begin{array}{l}\text { Consensus } \\
\text { splice site } \\
\text { score }\end{array}$ & $\begin{array}{c}\text { Consensus } \\
\text { splice } \\
\text { mutation } \\
\text { score }\end{array}$ & $\begin{array}{l}\text { Predicted } \\
\text { variation of } \\
\text { Cryptic Site } \\
\text { Position and } \\
\text { Score }^{c}\end{array}$ & $\begin{array}{l}\text { Consensus } \\
\text { splice site } \\
\text { score }\end{array}$ & $\begin{array}{c}\text { Consensus } \\
\text { splice } \\
\text { mutation } \\
\text { scoree }^{b}\end{array}$ & $\begin{array}{l}\text { Predicted } \\
\text { variation of } \\
\text { Cryptic Site } \\
\text { Position and } \\
\text { Score }^{c}\end{array}$ & $\begin{array}{l}\text { Consensus } \\
\text { splice site } \\
\text { score }\end{array}$ & $\begin{array}{c}\text { Consensus } \\
\text { splice } \\
\text { mutation } \\
\text { scoree }^{b}\end{array}$ & $\begin{array}{l}\text { Predicted } \\
\text { variation of } \\
\text { Cryptic Site } \\
\text { Position and } \\
\text { Score }^{c}\end{array}$ & $\begin{array}{l}\text { Consensus } \\
\text { splice site } \\
\text { score }\end{array}$ & $\begin{array}{c}\text { Consensus } \\
\text { splice } \\
\text { mutation } \\
\text { score }^{b}\end{array}$ & $\begin{array}{c}\text { Predicted } \\
\text { variation of } \\
\text { Cryptic Site } \\
\text { Position and } \\
\text { Score }\end{array}$ \\
\hline c. $-200-27 T>G$ & - & NA & NA & NA & A & - & - & & - & - & & - & & $\begin{array}{c}c .-200-42 \\
0.89 \\
(+4.7 \%) \\
\end{array}$ & - & - & $\begin{array}{c}c .200-42 \\
4.60 \\
(+0.2 \%) \\
\end{array}$ \\
\hline c. $-158 \mathrm{G}>\mathrm{C}$ & - & $\mathrm{NA}$ & $\mathrm{NA}$ & $\mathrm{NA}$ & A & - & - & & - & - & & - & - & & - & - & \\
\hline c. $-47 \mathrm{G}>\mathrm{A}$ & - & NA & NA & NA & A & - & - & $\begin{array}{c}\text { c.- } 46 \\
74.92 \\
(-100 \%)\end{array}$ & - & - & $\begin{array}{l}\text { c. }-465.71 \\
(-100 \%)\end{array}$ & - & - & & - & - & \\
\hline c. $212-58 \mathrm{~A}>\mathrm{C}$ & - & NA & NA & NA & A & 90.34 & 90.34 & & 10.02 & 10.02 & & 0.98 & 0.98 & & 7.88 & $\begin{array}{c}7.92 \\
(+0.4 \%)\end{array}$ & \\
\hline c. $620 C>G$ & p.Pro207Arg & $\begin{array}{l}\text { Probably } \\
\text { damaging }\end{array}$ & $\begin{array}{c}\text { Affect } \\
\text { protein } \\
\text { function } \\
\end{array}$ & $\begin{array}{l}\text { Class } \\
\text { C65 }\end{array}$ & A & 90.34 & 90.34 & $\begin{array}{c}c .623 \\
79.40 \\
(-100 \%) \\
\end{array}$ & 10.02 & 10.02 & $\begin{array}{r}c .623 \\
0.27 \\
(-94.9 \%) \\
\end{array}$ & 0.98 & 0.98 & & 7.88 & 7.88 & \\
\hline \multirow[b]{2}{*}{ c.1010T>C } & \multirow[b]{2}{*}{ p.Leu337Ser } & \multirow{2}{*}{$\begin{array}{l}\text { Possibly } \\
\text { damaging }\end{array}$} & \multirow{2}{*}{$\begin{array}{c}\text { Affect } \\
\text { protein } \\
\text { function } \\
\end{array}$} & \multirow{2}{*}{$\begin{array}{l}\text { Class } \\
\text { C65 }\end{array}$} & A & 90.34 & 90.34 & & 10.02 & 10.02 & & 0.98 & 0.98 & & 7.88 & 7.88 & \\
\hline & & & & & $\mathrm{D}$ & 87.54 & 87.54 & & 8.88 & 8.88 & & 0.99 & 0.99 & & 0.75 & 0.75 & \\
\hline \multirow{2}{*}{ c.1194G>A } & \multirow{2}{*}{ p.Val398Val } & \multirow{2}{*}{ NA } & \multirow{2}{*}{ NA } & \multirow{2}{*}{ NA } & A & $\begin{array}{l}90.34 \\
8754\end{array}$ & 90.34 & & 10.02 & 10.02 & & 0.98 & 0.98 & & 7.88 & 7.88 & \\
\hline & & & & & D & 87.54 & 87.54 & & 8.88 & 8.88 & & 0.99 & 0.99 & & 0.75 & 0.75 & \\
\hline c.1572A>G & p.Gln559Arg & Benign & Tolerated & $\begin{array}{l}\text { Class } \\
\text { C35 }\end{array}$ & $\mathrm{D}$ & 87.54 & 87.54 & & 8.88 & 8.88 & & 0.99 & 0.99 & & 0.75 & 0.75 & \\
\hline$c .1676 A>G$ & p.Gln559Arg & Benign & Tolerated & $\begin{array}{l}\text { Class } \\
\text { C35 }\end{array}$ & D & 87.54 & 87.54 & $\begin{array}{l}\text { c.1679 } 76.25 \\
(-1.1 \%)\end{array}$ & 8.88 & 8.88 & $\begin{array}{c}c .1679 \\
0.04 \\
(-100 \%) \\
\end{array}$ & 0.99 & 0.99 & & 0.75 & $\begin{array}{c}0.82 \\
(+8.2 \%)\end{array}$ & \\
\hline c. $1684+29 A>G$ & - & NA & NA & NA & D & 87.54 & 87.54 & & 8.88 & 8.88 & & 0.99 & 0.99 & & 0.75 & $\begin{array}{c}1.18 \\
(+56.9 \%) \\
\end{array}$ & \\
\hline c. $2014 G>C$ & p. Glu672Gln & Benign & $\begin{array}{l}\text { Affect } \\
\text { protein } \\
\text { function }\end{array}$ & $\begin{array}{l}\text { Class } \\
\text { C25 }\end{array}$ & D & 71.73 & 71.73 & & 7.09 & 7.09 & & 0.95 & 0.95 & & 2.36 & 2.36 & \\
\hline c. $2586+58 \mathrm{C}>\mathrm{T}$ & - & $\mathrm{NA}$ & NA & $\mathrm{NA}$ & D & 84.48 & 84.48 & & 6.80 & 6.80 & & 0.81 & 0.81 & & - & - & \\
\hline$c .2587-38 C>G$ & - & $\mathrm{NA}$ & $\mathrm{NA}$ & $\mathrm{NA}$ & A & 75.57 & 75.57 & & 3.31 & 3.31 & & - & - & & - & - & \\
\hline$c .2590 \mathrm{C}>\mathrm{T}$ & p.Pro864Ser & $\begin{array}{l}\text { Probably } \\
\text { damaging }\end{array}$ & Tolerated & $\begin{array}{l}\text { Class } \\
\text { C65 }\end{array}$ & A & 75.57 & 75.57 & & 3.31 & 3.31 & $\begin{array}{c}c .2597 \\
1.89 \\
(+11.2 \%) \\
\end{array}$ & - & - & $\begin{array}{c}c .2597 \\
0.65 \\
(+22.8 \%)\end{array}$ & - & - & \\
\hline c.2865T>A & p.Ser955Arg & Benign & $\begin{array}{c}\text { Affect } \\
\text { protein } \\
\text { function } \\
\end{array}$ & $\begin{array}{l}\text { Class } \\
\text { C65 }\end{array}$ & A & 77.22 & 77.22 & & 8.14 & 8.14 & & 0.54 & 0.54 & & 2.70 & $2.62(-2.9 \%)$ & \\
\hline$c .2993 G>A$ & p.Gly998GIn & $\begin{array}{l}\text { Probably } \\
\text { damaging }\end{array}$ & $\begin{array}{c}\text { Affect } \\
\text { protein } \\
\text { function }\end{array}$ & $\begin{array}{l}\text { Class } \\
\text { C65 }\end{array}$ & D & 85.40 & 85.40 & & 9.21 & 9.21 & & 0.99 & $\begin{array}{c}1.00 \\
(+1.0 \%)\end{array}$ & & 0.85 & $\begin{array}{c}1.31 \\
(+54.4 \%)\end{array}$ & \\
\hline$c .3300 T>G$ & p.Thr1100Thr & $\mathrm{NA}$ & NA & NA & $\mathrm{D}$ & 100.0 & 100.0 & & - & - & & - & - & & - & - & \\
\hline
\end{tabular}

- No predicted Donor or Aceptor site

${ }^{a} \mathrm{D}=$ Donor site; $\mathrm{A}=$ Aceptor site 
${ }^{\mathrm{b}}$ Variations in consensus splice sites are represented by its new score and in case of variation, the percentage of variation in parenthesis

${ }^{c}$ Indicated are cryptic splice sites for which at least two algorithms predicted a splice site score variation, and in parenthesis the percentage of variation 


\section{LEGENDS}

Figure 1. Bar charts of MLPA results. A: Profile of a normal control. B: Profile of the patient with the heterozygous deletion of exons 7-11 of PALB2 gene. C: Profile of a paraffine tumor sample from male with $B C$ relative of the $P A L B 2$ index case, also carrying the deletion. The grey bars represent the exons with the deletion.

Figure 2. Pedigree of the breast cancer family carrying the c.2587-?_3201+?del PALB2 mutation. Cancer diagnoses are indicated in those affected patients; in brackets the age at diagnosis or exitus. The arrow indicates the index case analysed. PALB2 mutation carriers are indicated by the + sign. BiBC: bilateral breast cancer, GC: gastric cancer

Supplementary figure 1. Co-segragation analysis of variants c.212-58A>C, c.1676A>G, c.2014G >C, c.2586+58C >T, c.2993G>A, c.3300T>G in one of the six carriers families. Individuals analysed are indicated by + and - signs: carriers of all the six variants in heterozygous state are indicated with a + sign, individuals that were not carriers of any of the variants are indicated with a - sign. *One family member was heterozygous for variants c.1676A>G and c. $2586+58 C>T$, only. Cancer diagnoses are indicated in the affected patient; in brackets the age at diagnosis or the actual age of the individual. 
Supplementary table 1. Participating centres and families from Spain

\begin{tabular}{lc}
\hline Center/Hospital & Number of families \\
\hline Hospital Universitario San Carlos (Madrid) & 27 \\
\hline Hospital Universitari Vall d'Hebron (Barcelona) & 14 \\
\hline Hospital de la Santa Creu i Sant Pau (Barcelona) & 13 \\
\hline $\begin{array}{l}\text { Fundación Pública Galega de Medicina Xenómica } \\
\text { (Galicia) }\end{array}$ & 11 \\
\hline Institut Català d'Oncologia & 11 \\
\hline Hospital Infantil Miguel Servet (Zaragoza) & 10 \\
\hline CNIO (Madrid) & 10 \\
\hline $\begin{array}{l}\text { Instituto de Biología y Genética Molecular (UVa-CSIC, } \\
\text { Valladolid) }\end{array}$ & 10 \\
\hline Hospital Universitario La Fe (Valencia) & 8 \\
\hline Hospital Sant Joan (Reus) & 131 \\
\hline Hospital de Cruces (Barakaldo) & \\
\hline Hospital Universitario Central de Asturias & \\
\hline Total & \\
\hline
\end{tabular}


Supplementary table 2. Sequences of PALB2 primers used for amplification and sequencing, lenght of the amplicon and melting temperature.

\begin{tabular}{|c|c|c|c|}
\hline PCR-fragment & Sequence & Length & Melting Temperature (으) \\
\hline \multirow{2}{*}{ EXON 1} & F-CAGAGATTCCGGCTACTTCC & \multirow{2}{*}{450} & \multirow{2}{*}{56} \\
\hline & R-GACACAAAGCCAGGCCTAAA & & \\
\hline \multirow{2}{*}{ EXONS $2 \& 3$} & F-GTGCTACTCCCTGCCTCTTG & \multirow{2}{*}{470} & \multirow{2}{*}{56} \\
\hline & R-CACACTGTGGGAAAAAGAACAA & & \\
\hline \multirow{6}{*}{ EXON 4} & F-GAACACATTCCTCCTAAAGGTAACA & \multirow{2}{*}{750} & \multirow{2}{*}{58} \\
\hline & R-GGAACTGTAGTCGCCCTGGT & & \\
\hline & F-CAGAACCAGTTACAGAAATTAATGAAG & \multirow{2}{*}{714} & \multirow{2}{*}{56} \\
\hline & R-TTGCATCCTTATTTTTATTTTTTAAACC & & \\
\hline & F-TAGCCTGGAAGCAACCTCTC & \multirow{2}{*}{717} & \multirow{2}{*}{58} \\
\hline & R-TTGAGCCAGGGTCTCACTCT & & \\
\hline \multirow{4}{*}{ EXON 5} & F-GAAGCTCACTCTTTGTTGGGTA & \multirow{2}{*}{614} & \multirow{2}{*}{56} \\
\hline & R-GTATGCTGGCTTTGCGAGTT & & \\
\hline & F-CGCATGGATACAGAAATGGA & \multirow{2}{*}{653} & \multirow{2}{*}{56} \\
\hline & R-TCAAAGAAACACGTCAAACCA & & \\
\hline \multirow{2}{*}{ EXON 6} & F-GTTTGCATTTGGAGCTTTGC & \multirow{2}{*}{300} & \multirow{2}{*}{56} \\
\hline & R-TAAAGAACAAGAAGCTATATGACTGAA & & \\
\hline \multirow{2}{*}{ EXON 7} & F-GCTCTTTCTTTTTCACCTGCAT & \multirow{2}{*}{398} & \multirow{2}{*}{56} \\
\hline & R-GCATGGTCATAGCTCCCAAT & & \\
\hline \multirow{2}{*}{ EXON 8} & F-TCCTTGTACAGTGAGAATACAAAAGAA & \multirow{2}{*}{260} & \multirow{2}{*}{56} \\
\hline & R-TGCACTTAAAACCAGCTGACA & & \\
\hline \multirow{2}{*}{ EXON 9} & F-AAAAGGTTACTCCTCACATCACC & \multirow{2}{*}{321} & \multirow{2}{*}{56} \\
\hline & R-ATTACACCCCCAGCACAGAA & & \\
\hline \multirow{2}{*}{ EXON 10} & F-CAGTTCAACAATGCGGAGAA & 328 & 56 \\
\hline & R-CAACAGCAACACAAAACCACA & उट0 & 50 \\
\hline EYON 11 & F-TTTCCCTGGTCACCTCCTAA & 290 & \\
\hline EAUIV 11 & R-CGGGGAAGGTTTGTTCATTA & 290 & 56 \\
\hline EXON 12 & F-GAGCCTATCGGTCATTGCTT & 361 & 56 \\
\hline LAUIV IL & R-TTTTCCATTCTTCTAAGTGACACAA & 301 & 50 \\
\hline & F-TGGTTTTGGGAACATGGTTT† & & \\
\hline EXON 13 & F- CCTGGAAGGTGACGTGAAAG* & 714 & 56 \\
\hline & R-TGAAATTTACACTTACTAGGCAAAGA & & \\
\hline
\end{tabular}

†Primer used only for amplification

*Primer used only for sequencing 
Figure 1

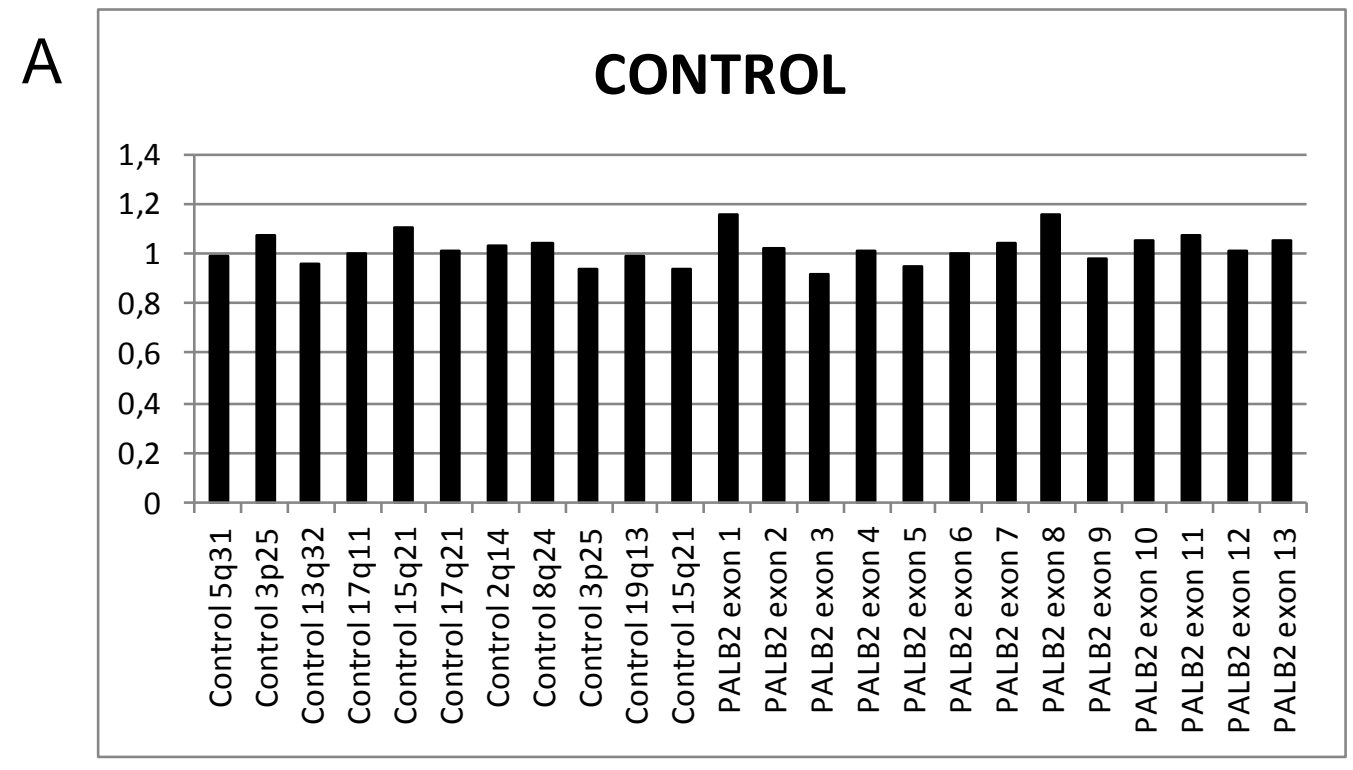

B

\section{CASE}

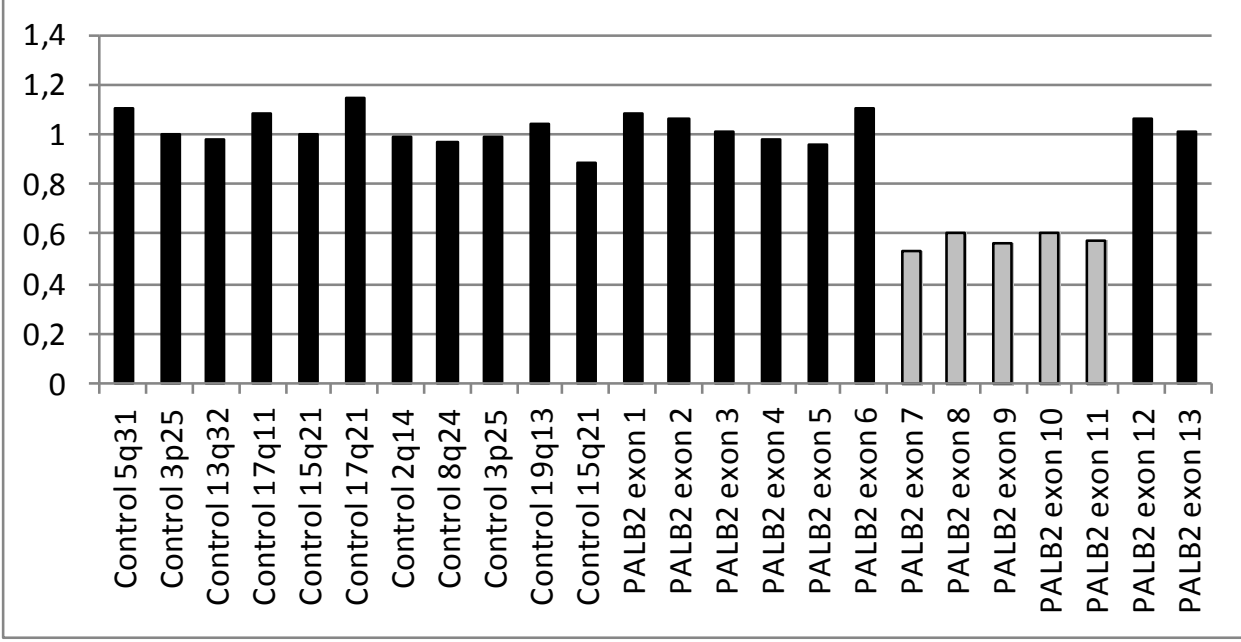

\section{PARAFFINE}

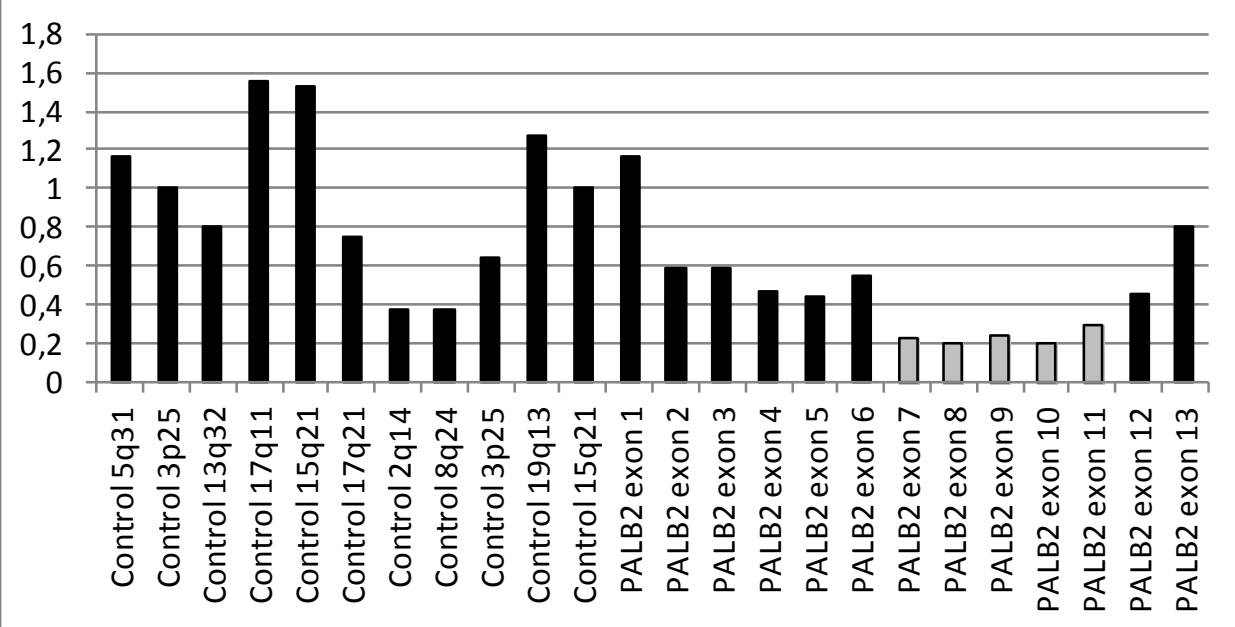


Figure 2

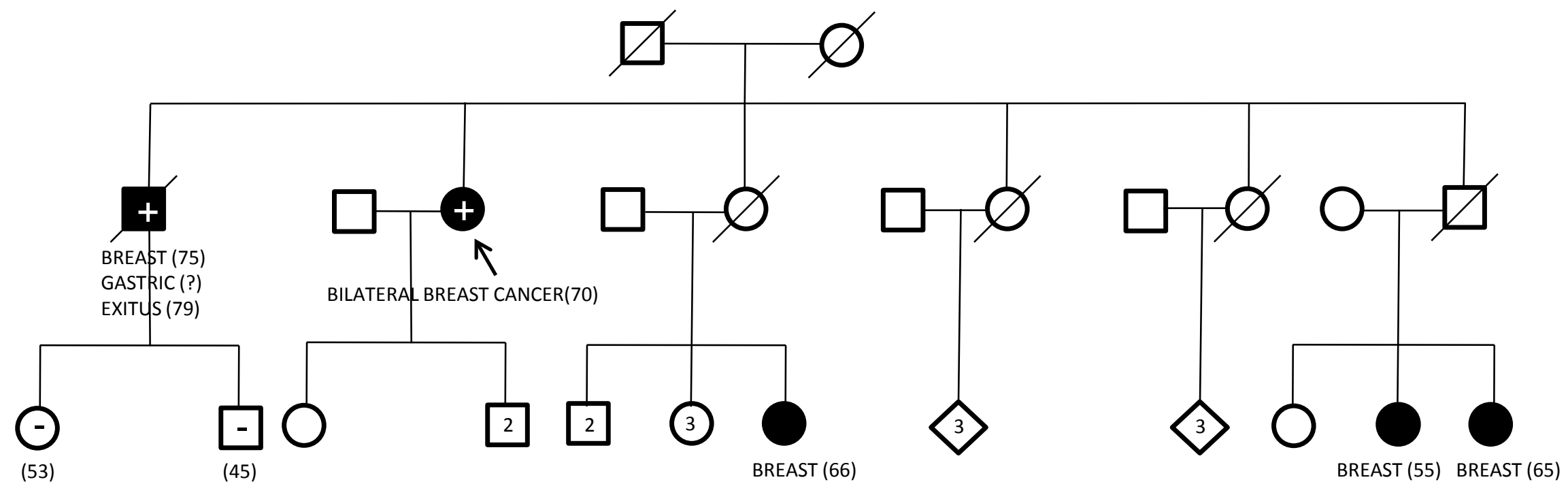




\section{Supplementary figure 1}

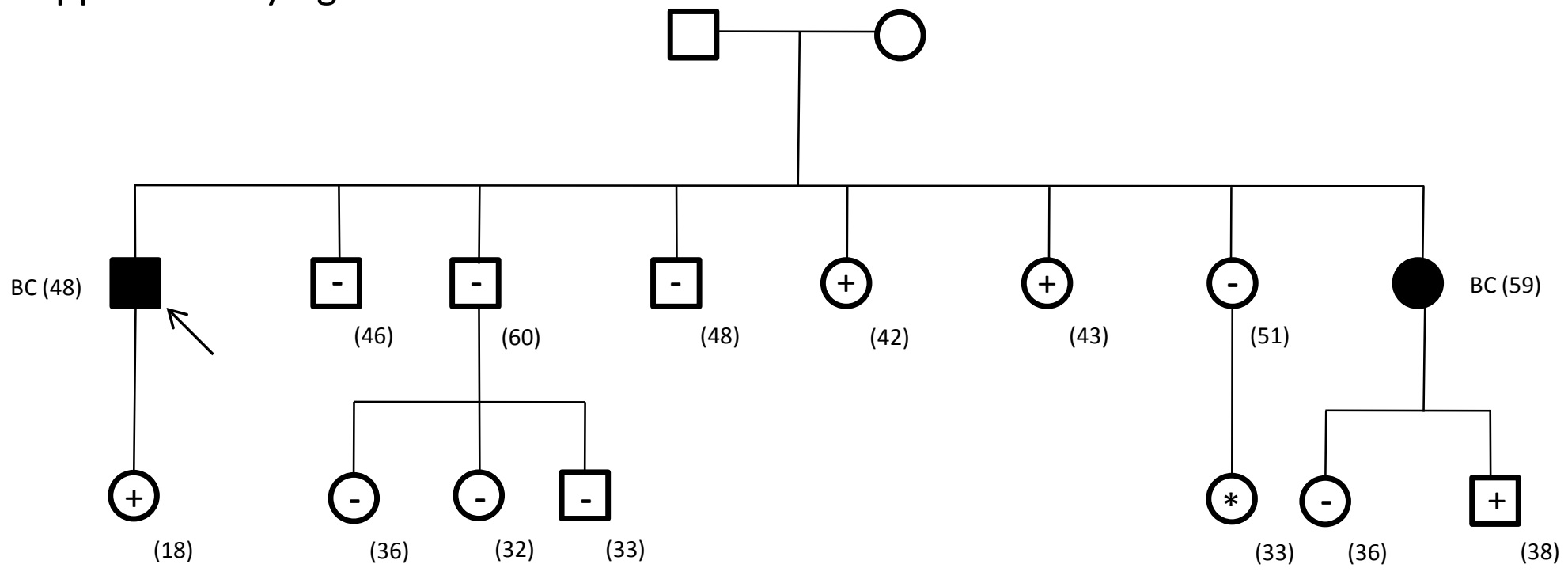

